\title{
Determination of thymidine phosphorylase expression level facilitates recurrence risk stratification in stage II/III colorectal cancer following adjuvant chemotherapy with oral fluoropyrimidines
}

\author{
NARUJI KUGIMIYA, EIJIRO HARADA, YUKI SUEHIRO, \\ ATSUSHI SUGA, YOSHIHIRO TAKEMOTO and KIMIKAZU HAMANO \\ Department of Surgery and Clinical Science, \\ Yamaguchi University Graduate School of Medicine, Ube, Yamaguchi 755-8505, Japan
}

Received September 26, 2018; Accepted March 18, 2019

DOI: $10.3892 /$ ol.2019.10181

\begin{abstract}
The present study aimed to prospectively clarify the prognostic effect of the expression of several genes that are known to modulate 5-fluorouracil effects in 63 patients who underwent curative resection for stage II/III colorectal cancer following adjuvant chemotherapy with oral fluoropyrimidines between 2008 and 2012. Thymidine phosphorylase (TP) expression in primary tumours was significantly lower in the recurrence group compared with the no-recurrence group $(\mathrm{P}=0.03)$, whereas, expression levels of genes that encoded thymidylate synthase, dihydropyrimidine dehydrogenase, folylpolyglutamate synthase, $\gamma$-glutamyl hydrolase and dihydrofolate reductase were not statistically different in tumours from the recurrence and no-recurrence groups. In the multivariate analysis using stepwise Cox proportional hazards regression, the following factors were significantly associated with shorter relapse-free survival following adjuvant chemotherapy with oral fluoropyrimidines: Venous invasion [present; hazard ratio $(\mathrm{HR})=6.51 ; 95 \%$ confidence interval (CI): 1.55-27.4; $\mathrm{P}=0.01)$, Tumour-Node-Metastasis stage (3b; $\mathrm{HR}=6.18 ; 95 \% \mathrm{CI}: 1.36-28.2 ; \mathrm{P}=0.02)$ and $\mathrm{TP}$ expression
\end{abstract}

Correspondence to: Dr Eijiro Harada, Department of Surgery and Clinical Science, Yamaguchi University Graduate School of Medicine, 1-1-1 Minami-Kogushi, Ube, Yamaguchi 755-8505, Japan E-mail: eharada@yamaguchi-u.ac.jp

Abbreviations: 5-FU, 5-fluorouracil; DHFR, dihydrofolate reductase; DPD, dihydropyrimidine dehydrogenase; FPGS, folylpolyglutamate synthetase; GGH, $\gamma$-glutamyl hydrolase; HR, hazard ratio; RFS, relapse-free survival; TNM, tumour-node-metastasis; TP, thymidine phosphorylase; TS, thymidylate synthase

Key words: TP, metabolic enzymes, oral fluoropyrimidines, colorectal cancer, adjuvant chemotherapy (low; HR=9.61; 95\% CI: 1.81-51.0; $\mathrm{P}=0.04$ ). Patients with two or more risk characteristics had significantly shorter 5-year relapse-free survival compared with patients with one or no risk characteristics (55.8 vs. 91.8\%; log-rank $\mathrm{P}=0.0006)$. We concluded that low TP expression is an independent predictive factor for poor prognosis in colorectal cancer. Therefore, determining TP expression may help to improve recurrence risk stratification in patients with stage II/III colorectal cancer following adjuvant chemotherapy with oral fluoropyrimidines.

\section{Introduction}

Colorectal cancer remains one of the most common malignant cancer worldwide and one of the leading causes of cancer-related deaths. Although the most effective treatment for colorectal cancer is surgery, which suppresses recurrence, patients with stage II/III colorectal cancer receive adjuvant chemotherapy after curative surgery (1). 5-Fluorouracil (5-FU) is one of the main chemotherapeutic agents for treating cancer, and oral fluoropyrimidines are widely used as postoperative adjuvant chemotherapy in Japan (2). However, factors that are predictive of patient prognosis in colorectal cancer remain unclear.

To establish adjuvant chemotherapy as precision medicine, it is necessary to clarify the relationship between the expression levels of enzymes affected by 5-FU or those that metabolise 5-FU or influence its effects on the one hand and the prognosis after adjuvant chemotherapy on the other hand. Thymidylate synthase (TS) is a target enzyme of 5-FU, and patients with advanced colorectal cancer and low TS mRNA or protein expression levels in primary tumours have been reported to respond better to 5-FU therapy than those with high TS levels (3-8). In contrast, low TS expression has been reported as a marker of poor prognosis after 5-FU-based adjuvant chemotherapy (9-12). Dihydropyrimidine dehydrogenase (DPD) is a 5-FU degrading enzyme, and among patients with advanced head and neck cancer, those with low DPD activity have experienced higher responses to 5-FU therapy (13). In advanced colorectal cancer, it has been reported that more 
accurate predictions of 5-FU therapy have been achieved by measuring tumour DPD expression level, in addition to those of TS and thymidine phosphorylase (TP) (14-19). TP, also known as platelet-derived endothelial cell growth factor, is a known angiogenesis factor related to the metabolism of 5-FU. Similar to the findings for TS, high TP mRNA expression levels in metastatic colorectal cancer have been associated with poor antitumour effects of 5-FU $(20,21)$. On the other hand, it has also been reported that colon cancer patients with high TP expression had a good prognosis after adjuvant chemotherapy $(7,22)$.

Folylpolyglutamate synthase (FPGS) is an enzyme that polymerizes glutamic acid and reduces folate. Reduced folic acid administered in vivo passes through the cell membrane as mono-glutamate, and inside the cell, FPGS polymerises mono-glutamate into polyglutamic acid, which is retained in the cell. $\gamma$-glutamyl hydrolase (GGH) is an enzyme that hydrolyses polyglutamate and reverses glutamate polymerisation activity of FPGS. GGH gene expression levels are inversely proportional to tumour tissue methylenetetrahydrofolate levels in patients with colorectal cancer. Therefore, the FPGS and GGH ratio affects the antitumour effect of 5-FU (23). Dihydrofolate reductase (DHFR) is an enzyme that reduces dihydrofolic acid, and the target of this enzyme, methotrexate, is a folic acid antagonist. The level of DHFR mRNA expression in tumour tissues has been reported to affect the strength of 5-FU anticancer effects (24).

In the present study, we performed adjuvant chemotherapy using oral fluoropyrimidines in patients with stage II/III colorectal cancer and investigated the relationship between expression levels of genes influencing 5-FU effects and prognosis.

\section{Patients and methods}

Patients and clinical samples. A total of 63 patients with colorectal cancer who underwent surgical treatment at the Yamaguchi University and affiliated hospitals between October 2008 and March 2012 were enrolled in this study. The inclusion criteria for this study specified histologically confirmed adenocarcinoma of the colon and rectum; Eastern Cooperative Oncology Group Performance Status Scale (ECOG-PS) 0 or 1; preserved organ function; underwent curative surgery; and possibility of administration of DPD inhibitor within 8 weeks after surgery. The exclusion criteria ruled out distant metastases and other cancer diagnosis. Written informed consent was obtained from all patients according to the Guidelines of the Medical Ethics Committee of the Yamaguchi University School of Medicine and approval was provided by Institutional Review Board of Yamaguchi University Hospital and the affiliated hospitals. This study is conducted in compliance with the principles of the Declaration of Helsinki and is registered in the University Hospital Medical Information Network Clinical Trials Registry in Japan (no. UMIN000003252). Patient samples were used in accordance with the Helsinki Declaration after written informed consent from all patients had been obtained.

Adjuvant chemotherapy regimens. Adjuvant chemotherapy using oral fluoropyrimidines was started within 6 weeks after surgery. The choice of the chemotherapy regimen was made by the patient, in consultation with the surgeon. In the uracil-tegafur (UFT)/leucovorin (LV) group, UFT (300 mg/m²/day as tegafur) and LV (75 mg/day) were simultaneously administered after meals, three times per day for 28 days, followed by a 7-day rest. This cycle was repeated for five courses. Following that treatment, UFT was administered after meals three times per day for 18 months. In the tegafur/gimeracil/oteracil (S-1) group, S-1 (80 mg/m²/day) was administered after meals twice per day for 28 days, followed by a 14-day rest. This cycle was repeated for four courses. Following that treatment, UFT was administered after meals three times per day for 18 months.

Reverse transcription-quantitative polymerase chain reaction $(R T-q P C R)$. Extracted fresh tissue specimens were fixed with $20 \%$ formalin for 3-5 days at room temperature. Ten micrometre-thick sections were obtained from the areas that were identified to have the highest concentrations of tumour cells and mounted on uncoated glass slides. For histological diagnosis, representative sections were stained with haematoxylin-eosin( haematoxylin for $10 \mathrm{~min}$ and eosin for $2 \mathrm{~min}$ ) at room temperature. Before microdissection, sections were deparaffinised in xylene for $10 \mathrm{~min}$ and hydrated with $100 \%, 95 \%$, and, finally, $70 \%$ ethanol solutions. Sections were then washed in water for $30 \mathrm{sec}$, stained with nuclear fast red (American MasterTech Scientific, Lodi, CA) for $20 \mathrm{sec}$, and rinsed again in water for $30 \mathrm{sec}$. Finally, samples were dehydrated with $70 \%, 95 \%$, and $100 \%$ ethanol solutions for $30 \mathrm{sec}$ each, followed by xylene for $10 \mathrm{~min}$. The slides were then completely air-dried. The sections of interest were selectively isolated by laser capture microdissection (P.A.L.M. Microsystem; Leica Microsystems GmbH, Wetzlar, Germany) according to a standard procedure (25).

Blinded tissue samples for subsequent extractions were placed in a $0.5-\mathrm{ml}$ thin-walled tube containing $400 \mu \mathrm{l}$ of $4 \mathrm{M}$ dithiothreitol-GITC/sarc (4 M guanidinium isothiocyanate, 50 mM Tris-HCl, pH 7.5, 25 mM EDTA) (Invitrogen; Thermo Fisher Scientific, Inc., Waltham, MA, USA; no. 15577-018). The samples were homogenised, and an additional $60 \mu \mathrm{l}$ of GITC/sarc solution was added. The samples were heated at $92^{\circ} \mathrm{C}$ for $30 \mathrm{~min}$ and then transferred to a 2-ml centrifuge tube. Fifty microliters of $2 \mathrm{M}$ sodium acetate $\mathrm{pH} 4.0$ was added, followed by $600 \mu 1$ of freshly prepared phenol/chloroform/isoamyl alcohol (250:50:1) mixture. The tubes were vortexed for $15 \mathrm{sec}$, placed on ice for $15 \mathrm{~min}$, and then centrifuged at $13,000 \mathrm{x} \mathrm{g}$ for $8 \mathrm{~min}$ in a chilled $\left(8^{\circ} \mathrm{C}\right)$ centrifuge. The upper aqueous phase was carefully removed and placed in a 1.5-ml centrifuge tube. Glycogen (10 $\mu \mathrm{l})$ and 300-400 $\mu \mathrm{l}$ of isopropanol were added, and the samples were vortexed for $10-15 \mathrm{sec}$. The tubes were chilled at $-20^{\circ} \mathrm{C}$ for $30-45 \mathrm{~min}$ to precipitate RNA. The samples were then centrifuged at $13,000 \mathrm{x} \mathrm{g}$ for $7 \mathrm{~min}$ at $8^{\circ} \mathrm{C}$. The supernatant was discarded, and $500 \mu \mathrm{l}$ of $75 \%$ ethanol was added. The tubes were again centrifuged at $13,000 \mathrm{x}$ g for $6 \mathrm{~min}$ in a chilled $\left(8^{\circ} \mathrm{C}\right)$ centrifuge. The supernatant was then carefully poured off, so as not to disturb the RNA pellet, and the samples were quick-spun for $15 \mathrm{sec}$ at $13,000 \mathrm{x}$. The remaining ethanol was removed, and the samples were left to air-dry for $15 \mathrm{~min}$. The pellet was resuspended in $50 \mu \mathrm{l}$ of $5 \mathrm{mM}$ Tris. Finally, cDNA was 


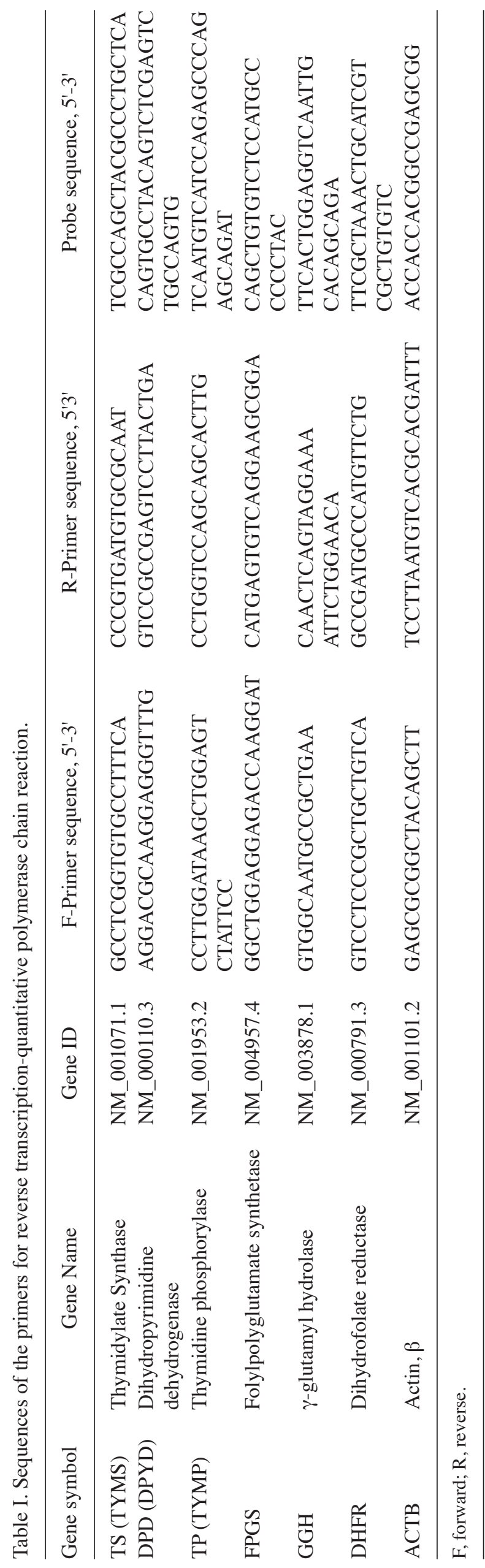

prepared based on the method by Lord et al (26). For cDNA synthesis, $20 \mu \mathrm{l} 5 \mathrm{X}$ Moloney murine leukemia virus (MMLV) buffer [containing $250 \mathrm{mmol} / \mathrm{l}$ Tris-HCl (pH 8.3), $375 \mathrm{mmol} / \mathrm{l}$ $\mathrm{KCl}$, and $15 \mathrm{mmol} / \mathrm{l} \mathrm{MgCl}_{2}$; Thermo Fisher Scientific, Inc.], $10 \mu 1$ dithiothreitol $(100 \mathrm{mmol} / \mathrm{l}$; Thermo Fisher Scientific, Inc.), $10 \mu \mathrm{ldNTP}$ (each $10 \mathrm{mmol} / \mathrm{l}$; Amersham Pharmacia Biotech), $0.5 \mu \mathrm{l}$ random hexamers [50 OD dissolved in $550 \mu \mathrm{l}$ of $10 \mathrm{mmol} / \mathrm{l}$ Tris- $\mathrm{HCl}$ (pH 7.5), and $1 \mathrm{mmol} / \mathrm{l} \mathrm{EDTA}$; Amersham Pharmacia Biotech, Piscataway, NJ, USA], $2.5 \mu \mathrm{l}$ bovine serum albumin [3 mg/ml in $10 \mathrm{mmol} / \mathrm{l}$ Tris-HCl (pH 7.5); Amersham Pharmacia Biotech], $2.5 \mu 1$ RNAse inhibitor (5 x 1,000 units; Amersham Pharmacia Biotech), and $5 \mu 1$ MMLV reverse transcriptase (200 U/ $\mu 1$; Thermo Fisher Scientific, Inc.), added to a total volume of $50.5 \mu$ l.

Quantification of six genes of interest and an internal reference gene encoding $\beta$-actin was performed using the fluorescence-based real-time detection method by a ABI PRISM 7900 Sequence detection system (Perkin-Elmer Applied Biosystems; Thermo Fisher Scientific, Inc.). PCR reaction mixture consisted of 1,200 nM of each primer; $200 \mathrm{nM}$ of the probe; $0.4 \mathrm{U}$ of AmpliTaq gold polymerase; $200 \mathrm{nM}$ of dATP, dCTP, dGTP and dTTP; and $3.5 \mathrm{mM}$ of $\mathrm{MgCl}_{2}$ and 1X TaqMan ${ }^{\circledR}$ buffer A, containing a reference dye. The final volume of the reaction mixture was $20 \mu \mathrm{l}$ (all reagents from Perkin-Elmer Applied Biosystems; Thermo Fisher Scientific, Inc.). Cycling conditions were $50^{\circ} \mathrm{C}$ for $2 \mathrm{~min}, 95^{\circ} \mathrm{C}$ for $10 \mathrm{~min}$, and 46 cycles of $95^{\circ} \mathrm{C}$ for $15 \mathrm{sec}$ and $60^{\circ} \mathrm{C}$ for $1 \mathrm{~min}$. The primers and probes used listed in Table I. TaqMan ${ }^{\circledR}$ measurements yield $\mathrm{Cq}$ values that are inversely proportional to the amount of cDNA in the tube. For example, a higher $\mathrm{Cq}$ value means that more PCR cycles are required to reach a certain level of cDNA detection. Gene expression values (relative mRNA levels) are expressed as ratios (differences between the $\mathrm{Ct}$ values) between the levels of gene of interest and that of the internal reference gene ( $\beta$-actin). The reference gene provides a baseline measurement for the amount of RNA isolated from a specimen. Taiho Pharmaceutical, Co., Ltd. (Tokyo, Japan) quantified gene expression by RT-qPCR.

Statistical analysis. Relapse-free survival (RFS) was defined as the time from the day of the surgery to the documented disease recurrence or death. Kaplan-Meier curves were used to estimate survival, and they were compared using the log-rank test. Each biomarker cut-off value was set at the median point. Differences between groups were analysed using the Student's t-test or $\chi^{2}$ test. The Cox proportional hazards regression model was used to identify variables associated with RFS. All statistical analyses were performed using SPSS (version 20; IBM Corp., Armonk, NY, USA) with a significance level of $\alpha=0.05(\mathrm{P}<0.05)$.

\section{Results}

Patients. From October 2008 and March 2012, a total of 63 patients met our inclusion criteria and were included for analysis. There were 45 men and 18 women, with a mean age of $68.0 \pm 9.3$ years. The median follow-up period for these patients was 73.2 months (5.4-105.2 months). A total of 42 patients received adjuvant chemotherapy with UFT/LV, and 21 patients received adjuvant chemotherapy with S-1. 
Table II. Patient characteristics and clinicopathological parameters.

\begin{tabular}{|c|c|c|c|}
\hline $\begin{array}{l}\text { Clinicopathological } \\
\text { variable }\end{array}$ & $\begin{array}{l}\text { Recurrence, } \\
n=14\end{array}$ & $\begin{array}{l}\text { No-recurrence, } \\
n=49\end{array}$ & P-value \\
\hline Age & $65.4 \pm 10.5$ & $68.7 \pm 9.0$ & 0.29 \\
\hline Sex & & & 0.04 \\
\hline Male & 13 & 32 & \\
\hline Female & 1 & 17 & \\
\hline ECOG-PS & & & 0.81 \\
\hline 0 & 13 & 43 & \\
\hline 1 & 1 & 5 & \\
\hline 2 & 0 & 1 & \\
\hline Tumor of location & & & 0.13 \\
\hline Right & 3 & 19 & \\
\hline Left & 4 & 19 & \\
\hline Rectum & 7 & 11 & \\
\hline Size of tumor, cm & $5.4 \pm 2.1$ & $5.8 \pm 2.1$ & 0.52 \\
\hline Histological grade & & & 0.56 \\
\hline Tub1 & 2 & 13 & \\
\hline Tub2 & 10 & 32 & \\
\hline Muci, poor & 2 & 4 & \\
\hline Lymphatic invasion & & & 0.05 \\
\hline Present & 14 & 38 & \\
\hline Absent & 0 & 11 & \\
\hline Venous invasion & & & 0.06 \\
\hline Present & 10 & 21 & \\
\hline Absent & 4 & 28 & \\
\hline T stage & & & 0.42 \\
\hline 2 & 2 & 3 & \\
\hline 3 & 7 & 33 & \\
\hline 4 & 5 & 13 & \\
\hline TNM stage & & & 0.001 \\
\hline 2 & 1 & 29 & \\
\hline $3 a$ & 8 & 16 & \\
\hline $3 b$ & 5 & 4 & \\
\hline $\begin{array}{l}\text { Adjuvant } \\
\text { chemotherapy }\end{array}$ & & & 0.83 \\
\hline UFT/LV & 9 & 33 & \\
\hline S-1 & 5 & 16 & \\
\hline
\end{tabular}

TNM, Tumor-Node-Metastasis; ECOG-PS, Eastern Cooperative Oncology Group Performance Status Scale; UFT/LV, uracil-tegafur/leucovorin.

Patients in the recurrence and no-recurrence groups had significantly different gender ratio $(\mathrm{P}=0.04)$ and tumour-node-metastasis (TNM) stage ( $\mathrm{P}=0.001$; Table II).

Comparison of the expression levels of genes modulating 5-FU effects in primary colorectal cancer tissues from the recurrence and no-recurrence groups. To investigate the expression levels of six genes modulating 5-FU effects in
63 primary colorectal cancer tissue samples, RT-qPCR was performed. The association between respective expression levels in the primary colorectal tumours of recurrence group and those of no-recurrence group was then investigated as presented in Fig. 1. TP expression in recurrence group tumours was significantly lower than that in no-recurrence group tumours ( $\mathrm{P}=0.03$; Fig. 1C). Expression levels of other studied genes were not statistically different between recurrence and no-recurrence groups (Fig. 1).

The association between the expression of each of the six genes of interest and clinicopathological parameters was then investigated. No significant correlations of the expression levels of these genes with any of the investigated clinicopathological parameters, including age, gender, tumour location, histological grade, invasion depth, lymphatic metastasis, lymphatic invasion, venous invasion or TNM stage were found (data are not shown).

Association between expression levels of genes modulating 5-FU effects and RFS. To investigate whether expression levels of genes modulating 5-FU effects in primary colorectal cancer tissues were associated with RFS following adjuvant chemotherapy with oral fluoropyrimidines, Kaplan-Meier analyses were performed as presented in Fig. 2. Kaplan-Meier analysis revealed that patients with low TP expression level experienced significantly shorter 5-year RFS (65.2 vs. 90.2\%, log-rank $\mathrm{P}=0.03$ ) than those with high TP expression level (Fig. 2C), whilst expression levels of other five genes examined did not affect RFS (Fig. 2).

Recurrence risk factor. In the univariate Cox proportional hazards regression analyses, the following variables were significantly associated with worse RFS: venous invasion [present; hazard ratio $(\mathrm{HR})=3.22,95 \%$ confidence interval $(\mathrm{CI}): 1.01-10.3$; $\mathrm{P}=0.049]$, TNM stage (3b; HR=5.19,95\% CI: 1.73-15.6; $\mathrm{P}=0.003)$, and TP expression (low; HR=3.86, 95\% CI: 1.08-13.9; $\mathrm{P}=0.04$; Table III). Furthermore, in the multivariate analyses based on the stepwise Cox model, venous invasion (present; $\mathrm{HR}=6.51$, 95\% CI: $1.55-27.4 ; \mathrm{P}=0.01)$, TNM stage $(3 \mathrm{~b} ; \mathrm{HR}=6.18,95 \% \mathrm{CI}$ : 1.36-28.2; $\mathrm{P}=0.02$ ) and TP (low; HR=9.61, 95\% CI: 1.81-51.0; $\mathrm{P}=0.04)$ remained significantly associated with worse RFS (Table III). We performed power analysis and Power was 0.34 in Cox proportional hazards regression of this study.

Recurrence risk characteristic strata. The three significant predictors from previous elimination analyses, namely venous invasion, TNM stage and TP expression level, were selected to generate the recurrence risk prediction model. The association between the number of risk features and RFS was also clearly indicated by the Kaplan-Meier curves (Fig. 3A). In addition, a clear inflection point towards worse outcomes was observed when patients had two or more risk characteristics. The patients with two or more risk characteristics had significantly shorter 5-year RFS (55.8 vs. $91.8 \%$, log-rank $\mathrm{P}=0.0006)$ than those with one or no risk characteristics (Fig. 3B).

\section{Discussion}

This study was designed to evaluate the relationship between expression levels of genes that are known to modulate 5-FU 

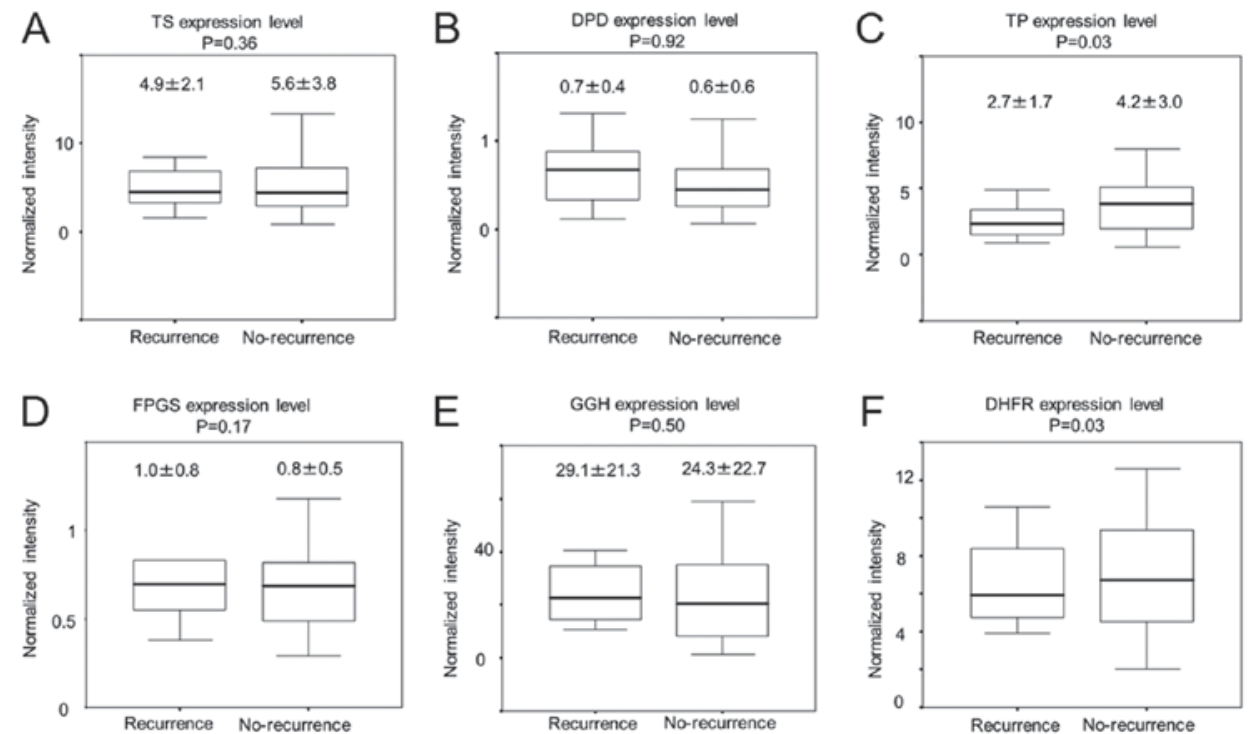

Figure 1. Comparison of the expression levels of genes known to influence 5-FU effects in primary colorectal cancer tissues, according to recurrence status. Expression levels of genes encoding (A) TS, (B) DPD, (C) TP, (D) FPGS, (E) GGH and (F) DHFR are compared in recurrence and no-recurence groups. TS, thymidylate synthase; DPD, dihydropyrimidine dehydrogenase; TP, thymidine phosphorylase; FPGS, folylpolyglutamate synthetase; GGH, $\gamma$-glutamyl hydrolase; DHFR, dihydrofolate reductase.
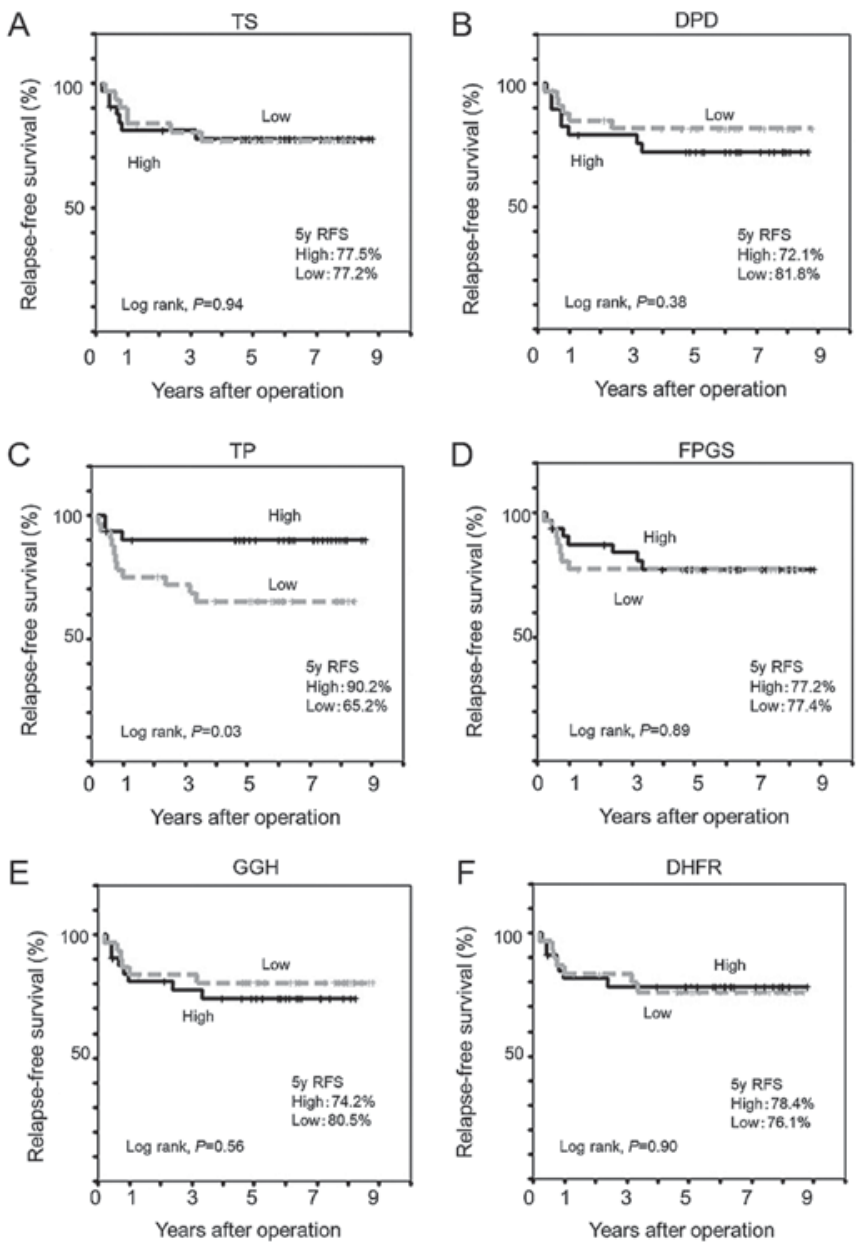

Figure 2. Kaplan-Meier estimates of relapse-free survival curves for colorectal cancer patients following adjuvant chemotherapy using a dihydropyrimidine dehydrogenase inhibitor. Relapse-free survival according to expression levels of genes encoding (A) TS, (B) DPD, (C) TP, (D) FPGS, (E) GGH and (F) DHFR. TS, thymidylate synthase; DPD, dihydropyrimidine dehydrogenase; TP, thymidine phosphorylase; FPGS, folylpolyglutamate synthetase; GGH, $\gamma$-glutamyl hydrolase; DHFR, dihydrofolate reductase. effects and prognosis in patients with stage II/III colorectal cancer after adjuvant chemotherapy with oral fluoropyrimidines. First, we investigated the relationship between the expression levels of the chosen six genes and recurrence status. Our data showed that only tumour TP expression in the recurrence group was significantly lower than that in the no-recurrence group. Additionally, RFS was significantly shorter in patients with low TP expression than in those with high TP expression.

TP has angiogenic activity and is one of the key metabolic enzymes of 5-FU $(21,27)$. There have been contradictory reports about the relationship between TP expression and colorectal cancer prognosis (27). It has been reported that patients with high TP expression have poor prognosis $(20,21)$. On the other hand, it has also been demonstrated that TP amplifies the sensitivity to anticancer agents $(18,22)$. The reason with such different reports is because TP has dual roles in cancer tissues. TP associated a promotion of angiogenesis and metastasis. However, high TP expression in tumor tissue may increase concentration of 5-FU in cancer tissues thorough angiogenesis and may contribute to the sensitivity of the DPD inhibitor through promoting phosphorylation of 5-FU. Recent meta-analysis indicated that low TP expression was associated with poor prognosis in 5-FU-based adjuvant chemotherapy (28). Consistent with this, our findings suggest that patients with low levels of TP mRNA in primary tumours had worse RFS than those with high levels of TP when adjuvant chemotherapy with oral fluoropyrimidine was administered. For patients with high TP levels, the recurrence rate may improve with the DPD inhibitor. Patients with low TP may not be monotherapy but may need doublet therapy, such as oxaliplatin or irinotecan. However, the effect of combination therapy with TP has not been studied. Further research is necessary in the future. The reason why patients with low TP expression have poor prognosis is still unclear. Further research is necessary to reveal why TP is a prognostic factor. 
Table III. Univariate and multivariate analyses of clinicopathological factors for correlations with relapse-free survival rate following adjuvant chemotherapy using oral fluoropyrimidines.

\begin{tabular}{|c|c|c|c|c|c|}
\hline $\begin{array}{l}\text { Clinicopathological } \\
\text { variable }\end{array}$ & $\mathrm{n}(\%)$ & $\begin{array}{c}\text { Univariate analysis, } \\
\text { HR }(95 \% \mathrm{CI})\end{array}$ & P-value & $\begin{array}{c}\text { Multivariate analysis, } \\
\text { HR }(95 \% \mathrm{CI})\end{array}$ & P-value \\
\hline \multicolumn{6}{|l|}{ Age } \\
\hline$\geq 70$ & $28(44.4)$ & $0.71(0.24-2.13)$ & 0.550 & & \\
\hline \multicolumn{6}{|l|}{ Sex } \\
\hline Male & $45(71.4)$ & $5.51(0.72-42.2)$ & 0.100 & $1.9(0.21-16.9)$ & 0.570 \\
\hline \multicolumn{6}{|l|}{ ECOG-PS } \\
\hline$\geq 1$ & $7(11.1)$ & $0.67(0.09-5.09)$ & 0.690 & & \\
\hline \multicolumn{6}{|l|}{ Tumor of location } \\
\hline Rectum & $18(28.6)$ & $2.79(0.98-7.98)$ & 0.060 & $1.93(0.64-5.80)$ & 0.240 \\
\hline \multicolumn{6}{|l|}{ Size of tumor } \\
\hline$\geq 5$ & $43(68.3)$ & $0.8(0.27-2.38)$ & 0.680 & & \\
\hline \multicolumn{6}{|l|}{ Histological grade } \\
\hline Poor & $6(9.5)$ & $2.4(0.54-10.8)$ & 0.250 & & \\
\hline \multicolumn{6}{|l|}{ Lymphatic invasion } \\
\hline Present & $52(82.5)$ & NE & & & \\
\hline \multicolumn{6}{|l|}{ Venous invasion } \\
\hline Present & $31(49.2)$ & $3.22(1.01-10.3)$ & 0.049 & $6.51(1.55-27.4)$ & 0.010 \\
\hline \multicolumn{6}{|l|}{ T stage } \\
\hline$\geq 4$ & $18(28.6)$ & $1.47(0.49-4.38)$ & 0.490 & & \\
\hline \multicolumn{6}{|l|}{ TNM stage } \\
\hline $3 b$ & $9(14.3)$ & $5.19(1.73-15.6)$ & 0.003 & $6.18(1.36-28.2)$ & 0.020 \\
\hline \multicolumn{6}{|c|}{ Adjuvant chemotherapy } \\
\hline S-1 & $21(33.3)$ & $1.02(0.34-3.06)$ & 0.970 & & \\
\hline \multicolumn{6}{|l|}{ TS } \\
\hline Low & $31(49.2)$ & $1.04(0.34-2.74)$ & 0.940 & & \\
\hline \multicolumn{6}{|l|}{ DPD } \\
\hline High & $29(46.0)$ & $1.61(0.56-4.63)$ & 0.380 & & \\
\hline \multicolumn{6}{|l|}{$\mathrm{TP}$} \\
\hline Low & $32(50.8)$ & $3.86(1.08-13.9)$ & 0.040 & $9.61(1.81-51.0)$ & 0.008 \\
\hline \multicolumn{6}{|l|}{ FPGS } \\
\hline Low & $31(49.2)$ & $1.07(0.38-3.06)$ & 0.890 & & \\
\hline \multicolumn{6}{|l|}{ GGH } \\
\hline Low & $31(49.2)$ & $0.73(0.25-2.11)$ & 0.560 & & \\
\hline
\end{tabular}

TNM, Tumor-Node-Metastasis; TS, thymidylate synthase; DPD, dihydropyrimidine dehydrogenase; TP, thymidine phosphorylase; FPGS, folylpolyglutamate synthetase; GGH, $\gamma$-glutamyl hydrolase; DHFR, dihydrofolate reductase; HR, hazard ratio; CI, confidence interval; NE, not estimated; ECOG-PS, Eastern Cooperative Oncology Group Performance Status Scale.

In this study, we also examined the impact of other genes influencing 5-FU effects, namely those encoding TS, DPD, FPGS, GGH and DHFR. No significant associations of their expression levels with prognosis or clinical outcomes were found.

Our most significant finding was that the number of high risk factors present form strata, which incrementally associate with recurrence in patients with stage II/III colon cancer, which received adjuvant chemotherapy with oral fluoropyrimidines. The venous invasion, TNM stage, and tumour TP expression were identified as significant predictive factors for RFS by multivariate analysis in the present prospective study. For patients with no risk factors or only one of them, the 5-year RFS rate was $91.8 \%$, which indicated successful suppression of the recurrence by the treatment. In contrast, for the patients with two or three risk factors, the 5-year RFS rate was 55.8\%. These patients may potentially benefit from receiving adjuvant chemotherapy, including oxaliplatin.

The current study had some limitations. First, we included a relatively small number of patients. Next, TP expression 

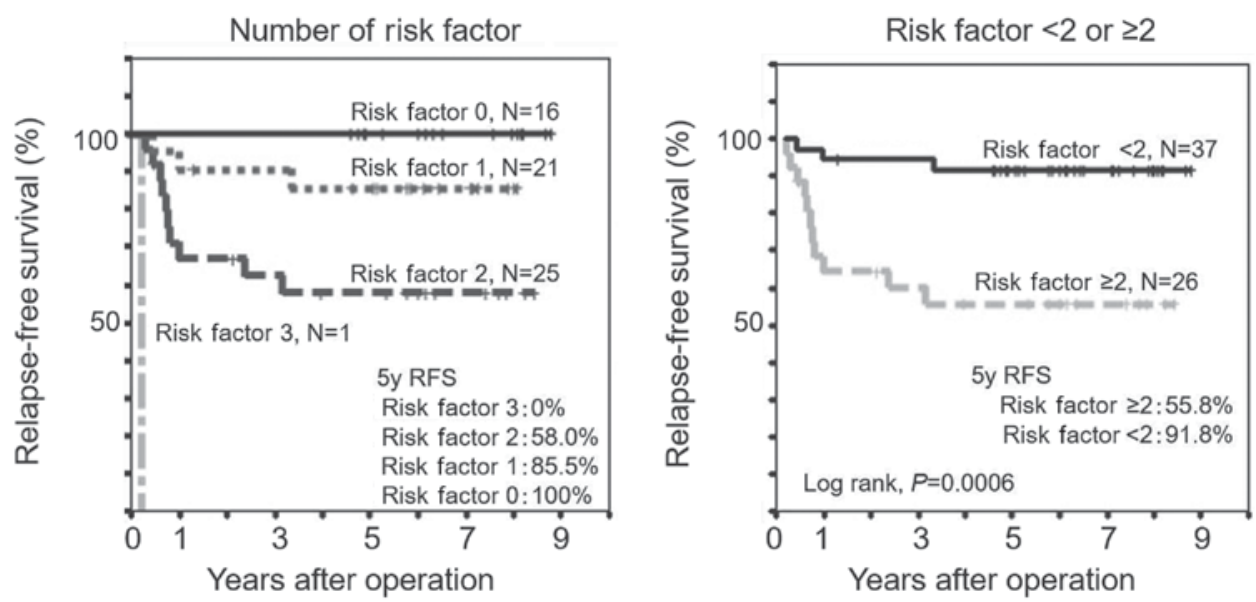

Figure 3. Kaplan-Meier estimates of relapse-free survival. Kaplan-Meier estimates of relapse-free survival curves depending on (A) the number of risk features and (B) at $<2$ factors vs. $\geq 2$ factors.

was inferred from mRNA levels in this study. TP activity and protein expression levels have not been investigated. The possibility is that expression levels of the protein does not accord with expression of the RNA. Another possibility is that the RT-PCR assessment is based on a small portion of the tumor field, but the whole field. It was wished I examined an evaluation in western blotting and immunohistochemistry. It is necessary to examine an evaluation in western blotting and immunohistochemistry. Moreover, our study included several adjuvant chemotherapy regimens, which were not randomised.

In conclusion, the present study revealed that low TP expression predicts poor colorectal cancer prognosis. Moreover, we succeeded in stratifying recurrence risk by identifying combinations of parameters such as venous invasion, TNM stage and tumour expression of TP, a 5-FU metabolizing enzyme, which were associated with poor prognosis in colorectal cancer.

\section{Acknowledgements}

The authors thank Dr T. Kato (Yamaguchi Rosai Hospital, Sanyo-Onoda, Japan), Dr A. Seyama (Syuto General Hospital, Yanai, Japan), Dr T. Takahashi (Yamaguchi Saiseikai Yamaguchi General Hospital, Yamaguchi, Japan), Dr K. Fujioka (Sanyo-Onoda Municipal Hospital, Sanyo-Onoda, Japan), Dr M. Orita (Hikari Municipal Hikari General Hospital, Hikari, Japan), Dr Y. Minami (Yamaguchi Saiseikai Shimonoseki General Hospital, Shimonoseki, Japan), Dr T. Kuga (Nagato General Hospital, Nagato, Japan), Dr S. Noshima (Yamaguchi Prefectural Grand Medical Center, Hofu, Japan), Dr S. Kobayashi (Ehime Rosai Hospital, Niihama, Japan), Dr M. Harada (Hikari Municipal Yamato General Hospital, Hikari, Japan) and Dr N. Akiyama (Tokuyama Central Hospital, Syunan, Japan) for their assistance in acquiring samples and collecting information from the patients with colorectal cancer.

\section{Funding}

The study was supported by Taiho Pharmaceutical, Co., Ltd. (Tokyo, Japan).

\section{Availability of data and materials}

The datasets used and/or analyzed during the current study are available from the corresponding author on reasonable request.

\section{Authors' contributions}

$\mathrm{EH}$ and $\mathrm{KH}$ contributed to the design and conception of the present study. NK, YT, YS and AS analyzed and interpreted the patient data.

\section{Ethics approval and consent to participate}

Written informed consent was obtained from all patients, according to the Guidelines of the Medical Ethics Committee of the Yamaguchi University School of Medicine (Yamaguchi, Japan) and approval was provided by the Institutional Review Board of Yamaguchi University Hospital (Ube, Japan) and the affiliated hospitals. The present study was conducted in compliance with the principles of the Declaration of Helsinki and is registered in the University Hospital Medical Information Network Clinical Trials Registry in Japan (no. UMIN000003252).

\section{Patient consent for publication}

Not applicable.

\section{Competing interests}

The authors declare that they have no competing interests.

\section{References}

1. Twelves C, Wong A, Nowacki MP, Abt M, Burris H III, Carrato A, Cassidy J, Cervantes A, Fagerberg J, Georgoulias V, et al: Capecitabine as adjuvant treatment for stage III colon cancer. N Engl J Med 352: 2696-2704, 2005.

2. Shimada Y, Hamaguchi T, Mizusawa J, Saito N, Kanemitsu Y, Takiguchi N, Ohue M, Kato T, Takii Y, Sato T, et al: Randomised phase III trial of adjuvant chemotherapy with oral uracil and tegafur plus leucovorin versus intravenous fluorouracil and levofolinate in patients with stage III colorectal cancer who have undergone Japanese D2/D3 lymph node dissection: Final results of JCOG0205. Eur J Cancer 50: 2231-2240, 2014. 
3. Leichman CG, Lenz H-J, Leichman L, Danenberg K, Baranda J, Groshen S, Boswell W, Metzger R, Tan M and Danenberg PV: Quantitation of intratumoral thymidylate synthase expression predicts for disseminated colorectal cancer response and resistance to protracted-infusion fluorouracil and weekly leucovorin. J Clin Oncol 15: 3223-3229, 1997.

4. Lenz H-J, Hayashi K, Salonga D, Danenberg KD, Danenberg PV, Metzger R, Banerjee D, Bertino JR, Groshen S, Leichman LP, et al: p53 point mutations and thymidylate synthase messenger RNA levels in disseminated colorectal cancer: An analysis of response and survival. Clin Cancer Res 4: 1243-1250, 1998.

5. Bathe OF, Franceschi D, Livingstone AS, Moffat FL, Tian E and Ardalan B: Increased thymidylate synthase gene expression in liver metastases from colorectal carcinoma: Implications for chemotherapeutic options and survival. Cancer J Sci Am 5: $34-40,1999$

6. Paradiso A, Simone G, Petroni S, Leone B, Vallejo C, Lacava J, Romero A, Machiavelli M, De Lena M, Allegra CJ, et al: Thymidilate synthase and p53 primary tumour expression as predictive factors for advanced colorectal cancer patients. Br J Cancer 82: 560-567, 2000.

7. Fujii R, Seshimo A and Kameoka S: Relationships between the expression of thymidylate synthase, dihydropyrimidine dehydrogenase, and orotate phosphoribosyltransferase and cell proliferative activity and 5-fluorouracil sensitivity in colorectal carcinoma. Int J Clin Oncol 8: 72-78, 2003

8. Ciaparrone M, Quirino M, Schinzari G, Zannoni G, Corsi DC, Vecchio FM, Cassano A, La Torre G and Barone C: Predictive role of thymidylate synthase, dihydropyrimidine dehydrogenase and thymidine phosphorylase expression in colorectal cancer patients receiving adjuvant 5-fluorouracil. Oncology 70: 366-377, 2006.

9. Johnston PG, Fisher ER, Rockette HE, Fisher B, Wolmark N, Drake JC, Chabner BA and Allegra CJ: The role of thymidylate synthase expression in prognosis and outcome of adjuvant chemotherapy in patients with rectal cancer. J Clin Oncol 12: 2640-2647, 1994.

10. Takenoue T, Nagawa H, Matsuda K, Fujii S, Nita ME, Hatano K, Kitayama J, Tsuruo T and Muto T: Relation between thymidylate synthase expression and survival in colon carcinoma, and determination of appropriate application of 5-fluorouracil by immunohistochemical method. Ann Surg Oncol 7: 193-198, 2000.

11. Edler D, Glimelius B, Hallström M, Jakobsen A, Johnston PG, Magnusson I, Ragnhammar P and Blomgren H: Thymidylate synthase expression in colorectal cancer: A prognostic and predictive marker of benefit from adjuvant fluorouracil-based chemotherapy. J Clin Oncol 20: 1721-1728, 2002.

12. Donada M, Bonin S, Nardon E, De Pellegrin A, Decorti G and Stanta G: Thymidilate synthase expression predicts longer survival in patients with stage II colon cancer treated with 5-flurouracil independently of microsatellite instability. J Cancer Res Clin Oncol 137: 201-210, 2011.

13. Etienne MC, Chéradame S, Fischel JL, Formento $P$, Dassonville O, Renée N, Schneider M, Thyss A, Demard F and Milano G: Response to fluorouracil therapy in cancer patients: The role of tumoral dihydropyrimidine dehydrogenase activity. J Clin Oncol 13: 1663-1670, 1995.

14. Salonga D, Danenberg KD, Johnson M, Metzger R, Groshen S, Tsao-Wei DD, Lenz HJ, Leichman CG, Leichman L, Diasio RB, et al: Colorectal tumors responding to 5-fluorouracil have low gene expression levels of dihydropyrimidine dehydrogenase, thymidylate synthase, and thymidine phosphorylase. Clin Cancer Res 6: 1322-1327, 2000.

15. Lassmann S, Hennig M, Rosenberg R, Nährig J, Schreglmann J, Krause F, Poignee-Heger M, Nekarda H, Höfler H and Werner M: Thymidine phosphorylase, dihydropyrimidine dehydrogenase and thymidylate synthase mRNA expression in primary colorectal tumors-correlation to tumor histopathology and clinical follow-up. Int J Colorectal Dis 21: 238-247, 2006.
16. Tokunaga Y, Sasaki H and Saito T: Clinical role of orotate phosphoribosyl transferase and dihydropyrimidine dehydrogenase in colorectal cancer treated with postoperative fluoropyrimidine. Surgery 141: 346-353, 2007

17. Ochiai T, Umeki M, Miyake H, Iida T, Okumura M, Ohno K, Sakamoto M, Miyoshi N, Takahashi M, Tsumura H, et al: Impact of 5-fluorouracil metabolizing enzymes on chemotherapy in patients with resectable colorectal cancer. Oncol Rep 32: 887-892, 2014

18. Mori T, Ohue M, Takii Y, Hashizume T, Kato T, Kotake K, Sato $\mathrm{T}$ and Tango T: Factors predicting the response to oral fluoropyrimidine drugs: A phase II trial on the individualization of postoperative adjuvant chemotherapy using oral fluorinated pyrimidines in stage III colorectal cancer treated by curative resection (ACT-01 Study). Oncol Rep 29: 437-444, 2013.

19. Koda K, Miyauchi H, Kosugi C, Kaiho T, Takiguchi N, Kobayashi S, Maruyama T and Matsubara H; Boso Clinical Oncology Group: Tumor 5-FU-related mRNA expression and efficacy of oral fluoropyrimidines in adjuvant chemotherapy of colorectal cancer. Anticancer Res 36: 5325-5331, 2016.

20. Metzger R, Danenberg K, Leichman CG, Salonga D, Schwartz EL, Wadler S, Lenz HJ, Groshen S, Leichman L and Danenberg PV: High basal level gene expression of thymidine phosphorylase (platelet-derived endothelial cell growth factor) in colorectal tumors is associated with nonresponse to 5-fluorouracil. Clin Cancer Res 4: 2371-2376, 1998.

21. Tokunaga Y, Hosogi H, Hoppou T, Nakagami M, Tokuka A and Ohsumi K: Prognostic value of thymidine phosphorylase/platelet-derived endothelial cell growth factor in advanced colorectal cancer after surgery: Evaluation with a new monoclonal antibody. Surgery 131: 541-547, 2002.

22. Saito S, Tsuno N, Nagawa H, Sunami E, Zhengxi J, Osada T, Kitayama J, Shibata Y, Tsuruo T and Muto T: Expression of platelet-derived endothelial cell growth factor correlates with good prognosis in patients with colorectal carcinoma. Cancer 88: 42-49, 2000.

23. Odin E, Wettergren Y, Nilsson S, Willén R, Carlsson G, Spears CP, Larsson L and Gustavsson B: Altered gene expression of folate enzymes in adjacent mucosa is associated with outcome of colorectal cancer patients. Clin Cancer Res 9: 6012-6019, 2003.

24. Satta T, Isobe K, Yamauchi M, Nakashima I, Akiyama S, Itou K, Watanabe $\mathrm{T}$ and Takagi $\mathrm{H}$ : Establishment of drug resistance in human gastric and colon carcinoma xenograft lines. Jpn J Cancer Res 82: 593-598, 1991

25. Bonner RF, Emmert-Buck M, Cole K, Pohida T, Chuaqui R, Goldstein S and Liotta LA: Laser capture microdissection: Molecular analysis of tissue. Science 278: 1481-1483, 1483, 1997.

26. Lord RV, Salonga D, Danenberg KD, Peters JH, DeMeester TR, Park JM, Johansson J, Skinner KA, Chandrasoma P, DeMeester SR, et al: Telomerase reverse transcriptase expression is increased early in the Barrett's metaplasia, dysplasia, adenocarcinoma sequence. J Gastrointest Surg 4: 135-142, 2000.

27. Bronckaers A, Gago F, Balzarini J and Liekens S: The dual role of thymidine phosphorylase in cancer development and chemotherapy. Med Res Rev 29: 903-953, 2009.

28. Che J, Pan L, Yang X, Liu Z, Huang L, Wen C, Lin A and Liu H: Thymidine phosphorylase expression and prognosis in colorectal cancer treated with 5-fluorouracil-based chemotherapy: A meta-analysis. Mol Clin Oncol 7: 943-952, 2017. 